\title{
GESTÃO DE MUDANÇAS E LIDERANÇA: ANÁLISE DE CASO ENVOLVENDO UMA INSTITUIÇÃO FEDERAL BRASILEIRA
}

\author{
João Batista Coelho \\ Mestrado em Sistemas de Gestão (MSG) \\ Laboratório de Tecnologia, Gestão de Negócios \& Meio Ambiente (LATEC) \\ Universidade Federal Fluminense (UFF) \\ Maria Alice Nunes Costa \\ Instituto de Arte e Comunicação Social (IACS) e \\ Programa de Pós-Graduação em Sociologia e Direito (PPGSD) da \\ Universidade Federal Fluminense (UFF)
}

\begin{abstract}
RESUMO
O objetivo deste estudo concentra-se na identificação de como os gestores (lideranças) atuaram na gestão de mudanças decorrente de um alinhamento estratégico que resultou na fusão de diversos setores de uma organização do poder público brasileiro. Foi realizada uma investigação empírica - com entrevistas semiestruturadas e aplicação de questionário - e comparados os resultados com a literatura existente a fim de observar como os gestores conduziram o processo de mudança organizacional. Dentre os achados figura a percepção de que a literatura científica serve como um bom parâmetro para o desenvolvimento de estudos preventivos que possam minimizar impactos em processos de gestões de mudanças. Este estudo contribui para a abordagem sobre a atuação de lideranças em gestões de mudança e em processos que demandem fusões setoriais, no sentido de que integra a literatura sobre organizações dos setores público e privado, enriquecendo a literatura e ampliando as possibilidades de observações sobre o tema. Fornece evidências empíricas sobre a atuação das lideranças nos níveis estratégico, tático e operacional, no âmbito da administração pública, colaborando para a redução de complexidades em processos similares por vir.
\end{abstract}

Palavras-chave: cultura organizacional, gestão de mudança, fusão setorial, liderança na gestão pública. 


\section{ABSTRACT}

\section{CHANGE MANAGEMENT AND LEADERSHIP: CASE ANALYSIS INVOLVING A BRAZILIAN FEDERAL INSTITUTION}

The focus of this study is to identify how leaders acted in the change management of a strategic alignment which resulted in the merger of several sectors of a public brazilian institution. An empirical investigation was conducted - with semi structured interviews and quiz application and the results were compared to existing literature in order to observe how the leaders drove the process of organizational change. Among findings is the perception that scientific literature is a good parameter for developing preventive studies able to minimize impacts on change management processes. This study contributes to the approach on the role of leaders in change management and in processes that demand sectoral mergers, in the sense that it integrates the literature on public and private sector organizations, enriching the literature and expanding the possibilities of observations on the subject. It provides empirical evidence on the role of leaders at the strategic, tactical and operational levels within the public administration, helping to reduce complexities in similar processes to come.

Keywords: organizational culture, change management, sectorial merger, leadership in public administration. 


\section{INTRODUÇÃO}

Este trabalho apresenta uma análise das práticas de liderança em um processo de gestão de mudanças em uma instituição pública brasileira. Neste propósito, realizou-se um survey junto aos servidores que integravam os setores de duas unidades administrativas, que passaram por um processo de fusão administrativa entre os anos de 2013 e 2016. Utilizou-se como instrumento de coleta de dados um questionário auto aplicado para 221 servidores que integraram esse processo de unificações setoriais, o qual envolveu 8 (oito) áreas distintas das duas organizações.

Um dos temas recorrentes no âmbito da administração pública no Brasil tem sido a permanente necessidade de se otimizar as práticas administrativas, a fim de que possa adotar estratégias da iniciativa privada e acompanhar as evoluções nos métodos gerenciais que guiam o mundo empresarial e, assim, modernizar a prestação de serviços públicos (BERGUE, p. 38,2020$)$.

As demandas por maior qualidade e agilidade na prestação de serviços vem se somando às exigências da sociedade para que o Estado reduza custos e fiscalize com austeridade os recursos utilizados pelas organizações públicas. A fim de satisfazer tais condições, faz-se visível que as modernas metodologias de gerenciamento, utilizadas na iniciativa privada, vêm sendo progressivamente incorporadas à gestão pública (ALVES, 2015; MATIAS-PEREIRA, 2014; NOGUEIRA et al., 2012).

A Emenda Constitucional no 19, de 4 de junho de 1998, estabeleceu, dentre outros, o Princípio da Eficiência na administração pública brasileira, passando a exigir que a atividade administrativa fosse "exercida com presteza, perfeição e rendimento funcional". (MEIRELLES, 2016). Em consonância com as determinações constitucionais, o Conselho Nacional de Justiça (CNJ), órgão que visa, dentre outros objetivos, o aperfeiçoamento do sistema judiciário, em 18/03/2009, emitiu a Resolução no 70, que definiu as diretrizes do planejamento estratégico nacional do Poder Judiciário brasileiro e um roteiro de gestão administrativa a ser seguido em todas as instâncias judiciárias do país, a fim de que a prestação jurisdicional, em sua totalidade, alcançasse níveis similares, e melhores, de eficiência. Em seu artigo 2ำ a resolução determinou que todos os tribunais brasileiros elaborassem seus planos estratégicos, adotando uma metodologia única, que trouxesse, para a estrutura organizacional do Judiciário, ferramentas, processos de trabalho e soluções também utilizados pela iniciativa privada. Para tanto, foram 
definidos, os macro desafios do Poder Judiciário Nacional, ou seja, metas a serem alcançadas. Foram propostos para o quinquênio de 2009 a 2014 e, posteriormente, revisados pelas Resoluções do CNJ no 198/2014 e no 325/2020, respectivamente, para os períodos de 2015 a 2020 e de 2021 a 2026.

Segundo Vasconcelos (2009), para que o planejamento estratégico ocorresse de forma adequada e as metas estipuladas pelo CNJ fossem cumpridas, cada unidade organizacional do Judiciário deveria estabelecer suas estratégias coerentemente alinhadas ao Plano Estratégico Nacional. Nesse sentido, um dos órgãos do Judiciário, visando à necessidade de aprimorar recursos materiais e humanos, e tendo como alvo a uniformização de procedimentos e a fixação de diretrizes únicas para a sua administração realizou um alinhamento institucional promovendo a junção de setores com atividades afins, de unidades organizacionais distintas. O alinhamento implicou a adoção de dependências únicas para o corpo funcional e na reestruturação de cargos e funções comissionadas. Assim, a partir de 2013, serviços administrativos similares que eram até então realizados simultaneamente pelas duas unidades, começaram a ser executados por setores únicos.

O alinhamento em questão, além de ter mobilizado fatores objetivos, de ordem material, envolveu aspectos de ordem humana. Consoante, houve reações pessoais em virtude de questões como os remanejamentos, temporários ou permanentes, de pessoal e local de trabalho, as trocas de chefias, as perdas de funções comissionadas, dentre outros motivos. Destarte, o processo envolveu o campo das percepções, dos valores individuais, assim como das identidades coletivas (grupais), convergindo para uma análise de como os gestores/lideranças atuaram na gestão de mudança.

O problema desta pesquisa origina-se, portanto, no aparente desempenho insatisfatório das lideranças em situações de gestão de mudanças nas instituições públicas brasileiras. Este trabalho apresenta uma análise das práticas de liderança no universo das organizações do poder público. Para isto, realizou-se um levantamento bibliográfico dos principais modelos de liderança e de gestão de mudanças e, a seguir, uma pesquisa do tipo survey junto aos stakeholders críticos, utilizando-se como instrumento de coleta de dados um questionário auto aplicado, com base na escala de Likert. (SILVA JUNIOR; COSTA, 2014).

Este artigo está dividido em quatro seções. A seção 1 faz uma revisão da literatura a fim de referenciar a pesquisa em sua trajetória de esclarecimentos, a partir dos problemas 
levantados; a 'seção 2', faz um delineamento da pesquisa e descreve os métodos utilizados para apurar os problemas levantados; a 'seção 3' faz uma análise e discute os resultados; e na 'seção 4' constrói-se a conclusão e sugestões para pesquisas futuras.

\section{REVISÃO DA LITERATURA}

Considerando que nas diretrizes do alinhamento institucional proposto para o Judiciário, priorizou-se a adoção de ferramentas e de soluções utilizadas pela iniciativa privada, ao tentar entender o papel das lideranças nos processos de gestão de mudança e de fusões organizacionais, examinaram-se fontes teóricas voltados para a administração pública e abordagens temáticas centradas no universo da gestão empresarial.

Drucker (1981), defendendo a necessidade de se ampliar a visão sobre o campo de aplicação da prática gerencial e da aferição de resultados destacou que nossa concepção de gestão se baseia na distinção que fazemos entre as organizações com fins lucrativos e as com fins sociais, mas para ele, a presença de um lucro convencional é uma diferença secundária entre as organizações. Destacou ainda que as entidades não empresariais, cujo fim último não é o lucro, por existirem para atender ou satisfazer algum tipo de necessidade ou interesse coletivo da sociedade, costumam sofrer, em seus quadros, carência de pessoal com aptidão ou conhecimento para exercerem os cargos de gerenciamento o que, consequentemente, possibilita o aparecimento de más gestões e planejamentos organizacionais precários (DRUCKER, 1981).

Para superar a carência de bons gestores nos quadros técnicos dos órgãos públicos, existe o recurso da livre nomeação de pessoas, que podem ocupar cargos de chefia ou assessoramento. Conhecidos como cargos de confiança, eles não criam vínculos estatutários e são regidos pela CLT (Consolidação das Leis Trabalhistas), ou seja, são de contratação direta e dispensam concurso público. Tais cargos estão previstos na Constituição Federal (Inciso XIII/Art. 40) e podem ser ocupados por pessoas do quadro institucional ou não.

No tocante à possibilidade de se fazer uso da livre contratação de pessoas para cargos comissionados, sejam elas servidores do quadro ou pessoas de fora da organização, faz-se visível na esfera da política brasileira, a frequente utilização de tais cargos como cabides de emprego, a fim de beneficiar protegidos políticos. Matias-Pereira, em Deda (2008), lembra que a livre nomeação, além de colaborar para a ineficácia administrativa, aumenta a 
possibilidade de corrupção na esfera do Poder Público, pois os indivíduos contratados para exercerem tais cargos, acabam criando apenas vínculos temporários, em decorrência das constantes mudanças políticas, não assumindo assim, de forma duradoura, "compromisso com a máquina pública, diferentemente do que ocorre com os concursados." Destaca ainda que há um excesso de cargos em comissão no país, e, à guisa de comparação, lembrou que na Inglaterra "o ministro só nomeia o seu secretário particular. Abaixo dele, todos os servidores são de carreira" (DEDA, 2008).

Ao criticar o crescimento do número de cargos comissionados no governo federal, Matias-Pereira lembrou que "quando loteiam cargos no governo, o critério não é de competência nem de postura ética. O critério é político." (SAMPAIO, 2015). Moreira (2009) destaca que a designação de pessoas, pautada apenas no relacionamento com quem as indica, sem respeitar o critério da competência técnica necessária ao cargo é tão ofensiva aos princípios constitucionais da administração - legalidade, impessoalidade, moralidade, publicidade e eficiência - quanto à pratica do nepotismo direto, vetada pela Súmula Vinculante $n$ o 13, do STF. No caso da designação pautada em critérios unicamente políticos, fruto de interesses subjetivos entre agentes públicos e privados existe a ideia de que tais conexões gerem perda de produtividade (COELHO \& BARROS, 2021).

Teixeira, Bassoti e Santos (2014), destacam, na administração pública brasileira, os apadrinhamentos como grandes dificultadores para a existência de gestões mais eficazes. Lembram que o modelo weberiano burocrático, que dá ênfase à eficiência, alcançada por meio da informalidade e impessoalidade, nunca foi plenamente aplicado em nosso país.

Após os processos de reforma por que passou a administração pública em diversos países do mundo, a partir da década de 1980, motivados pelo neoliberalismo que prosperou em conjunto com a interdependência global da economia, os princípios do modelo weberiano, passaram a ser considerados deficientes. Países como a Grã-Bretanha e diversos outros da Europa, EUA, Canadá, Austrália, Nova Zelândia, saíram na frente em busca de um modelo de gestão no setor público que seguissem regras que se aproximassem da iniciativa privada (FAGANELLO, 2017, p.47).

Muito tem se falado sobre a contínua necessidade de mudanças nas organizações a fim de acompanharem um mundo corporativo cada vez mais dinâmico e competitivo. Tais mudanças, recorrentemente acabam por implicar a necessidade de produção de novos sentidos, no que 
tange aos valores que direcionam e impulsionam a vida da organização. Esses valores são, assim, os reveladores de uma cultura organizacional.

Partindo de uma observação mais ampla sobre cultura organizacional, a fim de caminhar para uma aproximação maior com as questões implícitas na gestão de mudanças, há que se destacar pontos básicos da visão de três dos maiores pensadores da cultura organizacional. Hofstede (1991), ao falar de cultura organizacional destaca que a cultura é como uma programação mental, quando os indivíduos vão apreendendo, ao longo da vida, padrões de pensamento, sentimentos e propensões para agir. Essa programação é que distingue um grupo de outro. Organizacionalmente, a cultura reflete a forma como os funcionários foram socializados por sua organização de trabalho. Trompenaars (2000), por seu turno, enfatiza que uma determinada cultura organizacional não é nada mais do que a maneira pela qual os grupos se organizaram ao longo dos anos para resolver problemas e desafios que Ihes são apresentados. Schein (2009), ao adentrar em gestão de mudanças, destaca que os conceitos para se tornarem úteis devem partir de fatos observáveis e darem sentido ao que existe de misterioso e pouco entendido no campo comportamental e atitudinal na vida de grupos e organizações. Ao abordar a complexidade das mudanças culturais nas organizações, o autor conclui que a mudança cultural surge da necessidade de solucionar problemas organizacionais.

Sobre o tema, Bastos et al. (2011) apontam dois padrões de mudanças: episódico e contínuo. As episódicas se caracterizam como mais radicais, amplas, descontínuas e intencionais; as mudanças contínuas são demarcadas por sua frequência continuada e natureza incremental e não intencional. Estas últimas são fomentadas pelos processos de aprendizagem que se dão no decorrer das atividades diárias da organização.

Ao abordar os vínculos do indivíduo com a organização Pinho, Bastos e Rowe (2015) destacam que a literatura vem dedicando especial atenção ao tema do comprometimento e da obediência organizacionais. Inserem ao tema os construtos de "consentimento" e "entrincheiramento". Explicam entrincheiramento como sendo um processo de "aprisionamento do indivíduo à organização empregadora, um comportamento marcado pela acomodação, pois o empregado necessita se manter na organização em função dos benefícios que recebe e para garantir a própria sobrevivência". Os autores descrevem o consentimento como "uma condição de subserviência para o trabalhador, condição que o submete a uma 
avaliação negativa enquanto pessoa e profissional." Segundo eles, entrincheiramento e consentimento são reveladores de um quadro de adoecimento organizacional que envolve tanto o indivíduo como a organização.

Em pesquisa realizada por eles, onde aplicaram 400 questionários para servidores das administrações públicas Municipal, Estadual e Federal, incluindo órgão do Poder Judiciário, constataram que no tocante aos vínculos de comprometimento e entrincheiramento dos servidores públicos, há mais servidores comprometidos do que entrincheirados. Indivíduos casados, com filhos e alto grau de responsabilidade, apresentam nível de comprometimento e entrincheiramento altos e, também, quanto maior o nível educacional, mais alto é o nível de entrincheiramento (RODRIGUES E BASTOS, 2013).

Para Dom e Ahmad (2019), o desempenho organizacional é o resultado de uma empresa medido em relação às metas planejadas. Para os autores, é fundamental que os gestores de uma empresa entendam o desempenho organizacional para realizar uma mudança cultural. Kuipers, em Steijn et al. (2016), lembra que, em muitos órgãos do poder público, equipes são montadas a partir do entendimento de que, para que existam, basta juntarem mais que uma pessoa. Kuipers, destaca que "equipes são muito mais do que a soma de suas partes" e que não é tão simples pensar que, para a melhor execução de uma tarefa, seja suficiente uma equipe para se superar o desempenho do fazer individual.

Kuipers e Groeneveld (2014), em pesquisa voltada para o desempenho na Gestão Pública, com equipes distritais holandesas de profissionais que atuam para o bem-estar infantil, constataram que o grau de envolvimento dos profissionais, era invariavelmente, elevado. Perceberam a importância de três fatores para o sucesso: a cooperação entre os profissionais para alcançarem objetivos comuns; a colaboração orientada para as tarefas, onde se constatou que quanto maior a troca de informações e conhecimentos entre os profissionais, melhor era o desempenho das equipes e, no tocante à liderança, percebeu-se que onde existiam gerentes que melhor comunicassem a visão envolvida, dando autonomia para os membros individuais da equipe, melhor era o desempenho desta.

Agune (2014) projeta um escritório governamental do futuro e diz que em vez de salas isoladas deverá haver estímulos às atividades intersetoriais e transdisciplinar com utilização de novas mídias e tecnologias que permitam "flashs" instantâneos de problemas ou situações a serem enfrentados, substituindo relatórios burocráticos que só mascaram a realidade e 
postergam a ação de governo, e, também, a criação de laboratórios de gestão onde problemas inéditos, e/ou de alta complexidade poderão ser examinados em profundidade e de forma criativa, dando origem a protótipos de vários tipos - novos serviços, aplicativos internos, aplicativos para smartphones, metodologias para participação em mídias sociais, etc. (AGUNE, 2014).

Sena Neto (2019) menciona que embora comumente associe-se gestão governamental eletrônica apenas ao desenvolvimento das Tecnologias da Informação e Comunicação (TIC), a ideia de Governo Eletrônico traz consigo outras questões importantes como a ideia de controle social, quando a população passa a poder intervir diretamente nas ações públicas, opinando e participando da gestão pública.

Perides et al. (2020) enfatizam que o principal objetivo do gerenciamento de mudanças é minimizar o impacto da resistência à mudança. Sobre a resistência à mudança, Kuipers (2014) lembra que apesar de ser um tema comum na literatura de gestão de mudança, estudos vem mostrando que no âmbito da gestão pública a resistência à mudança ainda é uma questão importante, no entanto, não parece haver um consenso sobre o que provoca as resistências e como elas podem ser superadas (KUIPERS et al., 2014).

Aristos et al. (2018) em estudo focado na incorporação entre duas empresas da iniciativa privada, ao revisar a literatura com foco na resistência às mudanças, afirma ser esse um grande desafio e demonstra que a literatura aponta os impactos culturais como grandes responsáveis pelos insucessos das fusões. Phul e Procópio (2014), em estudo de caso sobre a administração do Poder Judiciário Federal, apontam este Poder como o mais resistente a mudanças no Brasil, entretanto lembram que as modernizações organizacionais ganharam força com o processo de democratização do país, após Constituição de 1988.

Kuipers (2014), citando Oreg (2007), que validou uma escala de resistência à mudança, destacou que encontrou na personalidade e no contexto da mudança os motivos para as resistências. Segundo ele, funcionários públicos resistem às mudanças, porque antecipam resultados indesejados, mas lembra que Vann (2004) não considera que as expectativas dos funcionários possam ser influentes. Kuipers conclui que é necessário examinar a evolução das respostas do funcionário às mudanças ao longo do tempo, ou seja, compreender as respostas que surgem de baixo para cima. Kuipers destaca que Branco (2000) aponta a estratégia de gestão de mudança como a chave para o sucesso e evidencia que uma abordagem de 
gerenciamento de mudanças de cima para baixo não funciona porque leva os funcionários a um processo de muita resistência.

Pieterse (2012), indo além das respostas dos funcionários aos processos de mudança, centrou-se nas possíveis diferenças presentes na linguagem usada pelos profissionais que trabalham em projetos de mudança e inovação. Ele evidencia que apesar das organizações mudarem e se adaptarem continuamente para se manterem competitivas, a eficácia em mudanças organizacionais ainda é muito baixa. Ele lembra que estatísticas recentes revelam que apenas um terço dos esforços de mudança organizacional foram considerados bem sucedidos.

Pieterse et al. (2012) aborda os processos de mudança a partir de uma perspectiva do discurso e argumenta que cada programa de mudança contém dimensões subjetivas que envolvem produção de sentido e interações informais. Para ele, a maneira como as pessoas interpretam um projeto de mudança é refletida na linguagem. Quando diferentes grupos profissionais que cooperam num programa de mudanças dão significados diferentes para a situação da mudança, essas diferenças podem resultar em resistências.

Hameed et al. (2019) em sua pesquisa sobre gestão de mudanças no setor público, partindo do pressuposto de que fatores contextuais, como comunicação envolvida, afetam a capacidade cognitiva dos funcionários, concluem que funcionários com uma identificação organizacional (OID) forte, são mais propensos a aceitarem mudanças e que as incertezas em torno da mudança podem dificultar o processo de mudança. Voet, Kuipers e Groeneveld (2013), dizem que em um processo planejado de mudança, a elevada qualidade da comunicação e o alto grau de participação devem ambos ser esperados a fim de influenciar positivamente o compromisso afetivo dos funcionários para mudarem. Destacam que o papel da liderança é geralmente visto como essencial durante a execução da mudança organizacional, mas a atenção fica muitas vezes focada na alta administração ou na equipe de coalizão administrativa da mudança. Além disso, pautados em Holt, Armenakis, Feild \& Harris (2007) lembra que o apoio da alta gerência é de suma importância para a iniciativa de mudar. Mencionam ainda que embora o papel da alta administração seja frequentemente enfatizado durante o início da mudança, supervisores diretos desempenham um papel muito importante durante a implementação da mudança (VOET; KUIPERS; GROENEVELD, 2013)." 
Cameron (2008) parte do pressuposto de que toda mudança organizacional não requer apenas liderança, mas também "campeões" e "proprietários". Para ele as mudanças de cultura não correm frouxas nas organizações, elas demandam a presença de líderes que ajam e dirijam todo o processo de forma consistente. Ele destaca, dois postos-chaves que devem ser considerados. Um deles é que cada aspecto do processo da mudança de cultura (iniciativa estratégica, processo de comunicação etc.) precisa de um campeão ou alguém que aceite a sua propriedade a fim de que a implementação da mudança seja bem-sucedida. A responsabilidade será também mais bem mantida quando designada uma equipe de "proprietários" da iniciativa, pois este conjunto de indivíduos garantirá maior participação e compromisso. Lembra ainda que não somente os líderes atuais da organização devem defender a mudança, mas um grupo de futuros líderes deve estar preparado para liderar a organização quando a mudança de cultura for colocada em prática. Menciona que pesquisadores contemporâneos abordam a liderança como uma forma de interação social que envolve componentes afetivos, motivacionais, éticos, atitudinais dentre outros.

Tee, Ashkanasy e Paulsen (2013) destacam que na última década houve um aumento da percepção do importante papel que as emoções desempenham na relação lideresseguidores. As pesquisas vêm se liberando do pressuposto de que apenas a lógica e a racionalidade são objetos importantes de observações nos processos de liderança. Tse, Ashkanasy e Dasborough (2012) abordam a visão de que as relações de troca interpessoais entre os líderes, os subordinados e os colegas de trabalho estão interligados e incorporados dentro de uma rede social maior nas organizações. Eles sugerem que estas relações de trocas são interdependentes e podem exercer influências mútuas. Apontam, em particular, a qualidade diferencial das relações descritas na Teoria LMX, de Intercâmbios entre Líderes e Membros, que analisa a amplitude das negociações líder-membro a partir de referenciais psicológicos de comparação interpessoal. Eles postulam que a identificação social tem o potencial de aumentar a auto compreensão que está relacionada com a forma como os funcionários se percebem e se imaginam em um grupo de trabalho e que, por conseguinte, também podem estar associadas às suas reações comportamentais.

Yukl (2013) entende a liderança como sendo "o processo de influenciar os outros a entender e concordar sobre o que precisa ser feito e como fazê-lo, e o processo de facilitar os esforços individuais e coletivos para alcançar os objetivos compartilhados". Em HASSAN et al. 
(2013), Yukl fala das lideranças éticas e do "empoderamento" de lideranças - que seria a delegação de confiança do gestor a funcionários capacitados para decidirem em seu lugar quando estiverem ausentes. Em tempos atuais de crises financeiras, recessões e constantes escândalos envolvendo líderes de organizações privadas e governamentais, a ética, a superação da dependência e a liberdade para decidir passaram a ser valorizados.

Para Banks et al. (2021), a liderança ética e suas práticas continuarão ganhando relevância no século XXI. HASSAN et al. (2013), dizem que a ética e o "empoderamento" de membros da organização são comportamentos suscetíveis de serem associados com a alta qualidade de relacionamentos de troca líder-membro da LMX. Liderança ética e liderança "empoderada", na LMX, podem estar associadas a uma variedade de resultados importantes, incluindo a motivação subordinada, a satisfação, o desempenho, os comportamentos pró-sociais entre outros. Líderes com relações de troca favoráveis são mais propensos a serem percebidos como eficazes e capazes de induzirem os subordinados a compromissos afetivos com a organização. Para HASSAN et al. (2013) as relações de troca de alta qualidade são mais prováveis de ocorrer quando os líderes são honestos, dignos de confiança, e genuinamente preocupados com o bem-estar de seus seguidores.

Segundo Kavanagh e Ashkanasy (2006), os autores Van Knippenberg e Hogg (2003) e Van Dick (2004) argumentam que, em grupos de alta relevância com os quais as pessoas se identifiquem fortemente, a eficácia da liderança é significativamente influenciada pela forma como o líder é percebido pelos membros do grupo. E ainda ressaltam que Conger e Kanungo (1988) e Kotter (1988) enfatizam que os líderes precisam entender que a gestão se refere a processos de planejamento, organização e controle, enquanto a liderança é o processo de motivar as pessoas a mudar.

Salem et al. (2019), somam aos desafios a exigência de que os líderes reconheçam e respeitem proativamente as identidades de subgrupos distintos na cultura da organização. Segundo Hoog, Van Knippenberg e Rast (2012), um dos achados mais robustos da pesquisa sobre o comportamento intergrupal é que os grupos definem quem somos. O desafio para a liderança intergrupal é superar práticas competitivas e abrandar as diferenças entre os grupos, a fim de construir a cooperação e colaboração a serviço de uma visão única e de mesmos propósitos. Eles lembram que é a percepção subjetiva dos membros que impulsiona os comportamentos intergrupais. 
Citando Nadler, Thies e Nadler (2001), Kavanagh e Ashkanasy (2006) lembram que para que ocorram mudanças efetivas e, em particular, mudanças culturais, é imprescindível o envolvimento ativo do CEO e da equipe executiva. A esse posicionamento pode-se associar o resultado das investigações de Collins (2011) que revelou que os melhores líderes são pessoas humildes, capazes de se sacrificarem em nome da organização e de abrirem mão de seu bemestar pessoal visando o bem comum da organização (COLLINS, 2011).

Kavanagh e Ashkanasy (2006) consideram a necessidade de se observar as gestões de topo, pois muitas fusões se perdem por estarem mal enquadradas pelo topo. Lembram que Weber (1989 e 1996) e Weber, Schweiger e Lubatkin, (1992), dizem que quando em uma fusão por aquisição existem diferenças culturais entre as equipes de topo, e se são percebidas pelo parceiro não dominante (empresa adquirida), grandes problemas de recursos humanos serão experimentados pela adquirente (KAVANAGH; ASHKANASY, 2006 apud WEBER, 1989 e 1996 e WEBER; SCHWEIGER; LUBATKIN, 1992).

Weber (2011), relata que os pesquisadores de comportamento organizacional afirmam que a principal causa de falhas em fusões e aquisições é a desatenção com o fator humano durante o processo de planejamento e implementação da fusão. Dirva e Radulescu (2018) em caminho parecido, atribuem a causa do insucesso nos mesmos processos à relutância do funcionário em mudar. Weber (2015) conclui que os processos de fusões de empresas, apesar de cada vez mais intensificados no mundo inteiro, vêm apresentando um histórico de baixo desempenho e a apuração dos motivos desses maus resultados ainda deixa muito a desejar, mantendo-se parcialmente incógnitos.

Lubis \& Hanum (2020) destacam que uma cultura forte se refletirá no alto desempenho organizacional e para finalizar, vale lembrar o clássico Trompenaars (2000), que ao conceituar cultura organizacional cita que uma cultura é relativamente estável quando as normas refletem os valores do grupo. Se não for este o caso, muito provavelmente haverá uma tensão desestabilizadora.

\section{METODOLOGIA}

A pesquisa foi estruturada a partir das relações entre gestores/lideranças e colaboradores que se estabeleceram no universo das fusões setoriais ocorridas, configurando- 
se destarte o objeto de estudo como um fenômeno ativo, onde os sujeitos entrevistados afirmavam valores diante das mudanças. Para conduzir o presente estudo, formulou-se então as seguintes questões norteadoras: “'questão (i)' Existe alinhamento entre as práticas de liderança identificadas na pesquisa de campo e a literatura científica sobre o tema?" e “'questão (ii)’ Quais as deficiências das lideranças em processos de mudança administrativa em instituições públicas?"

De caráter descritivo-exploratório, a pesquisa foi realizada de janeiro a maio de 2016 e teve como objeto de estudo a atuação das lideranças em processo de gestão de mudanças caracterizado por fusões setoriais no âmbito da administração pública, tema pouco explorado, que por si, já se insere nas premissas metodológicas do ineditismo em pesquisa. O objetivo foi avaliar o alinhamento entre práticas e teoria, confrontando a práxis do processo estudado com os referenciais teóricos vinculados à temática (VAGARINHO, 2019).

O método de pesquisa adotado foi o survey, que tem por objetivo a descrição de fenômenos através da coleta estruturada de dados, com a utilização de questionários ou entrevistas (BRYMAN, 1989). É um método que permite a participação de um número grande de entidades, sem a intervenção direta do pesquisador na coleta de dados. E diante da mencionada carência de pesquisas voltadas para as fusões organizacionais no setor público, e no Poder Judiciário, que tivessem estudado a atuação de lideranças em gestões de mudanças, a abordagem quali-quantitativa se fez mais apropriada, destarte foram realizadas entrevistas semiestruturadas e aplicação de questionários, com o intuito de abranger todos os níveis de gestão: estratégico, tático e operacional.

$\mathrm{Na}$ impossibilidade de entrevistar individualmente todos os integrantes do universo estudado, foram realizadas 6 (seis) entrevistas semiestruturadas com 2 (dois) magistrados, 2 (dois) gestores e 2 (dois) servidores, considerando-se a posição estratégica e o nível de participação destes no processo estudado. Foram assim coletados, por meio de gravação, um total de 4 horas e 34 minutos de depoimentos.

As entrevistas semiestruturadas serviram para se obter um melhor entendimento do processo e orientar na elaboração do questionário único. Nelas, foram considerados aspectos interligados ao processo, das primeiras comunicações oficiais sobre o alinhamento até as ações estratégicas em curso. Como roteiro guia, foram elaboradas as 18 perguntas a seguir: 
Figura 1: Roteiro guia das entrevistas semiestruturadas

\begin{tabular}{|c|c|c|}
\hline \multicolumn{2}{|c|}{ Perguntas básicas: } & \multirow[t]{2}{*}{ Observações } \\
\hline 01 & $\begin{array}{l}\text { Como o(a) senhor(a) tomou } \\
\text { conhecimento da decisão de se fundir } \\
\text { setores? }\end{array}$ & \\
\hline 02 & Como o(a) senhor(a) reagiu? & \\
\hline 03 & $\begin{array}{l}\text { Qual foi sua primeira impressão a } \\
\text { respeito dessa decisão? }\end{array}$ & \\
\hline 04 & $\begin{array}{l}\text { Como o corpo funcional/ os seus } \\
\text { funcionários/ os colegas reagiram à } \\
\text { decisão? }\end{array}$ & Dependendo se juiz, gestor ou funcionário \\
\hline 05 & $\begin{array}{l}\text { O que é a fusão para o(a) senhor(a) em } \\
\text { uma única palavra? }\end{array}$ & \\
\hline 06 & $\begin{array}{l}\text { Quais foram os principais desafios } \\
\text { enfrentados no processo de fusão? }\end{array}$ & \\
\hline 07 & Quais os pontos fortes da fusão? & \\
\hline 08 & E os pontos fracos? & \\
\hline 09 & $\begin{array}{l}\text { Houve resistências à fusão em seu } \\
\text { setor? }\end{array}$ & \\
\hline 10 & Quais foram as resistências? & \\
\hline 11 & E quais as motivações? & \\
\hline 12 & $\begin{array}{l}\text { Qual foi a solução encontrada para resolver } \\
\text { os conflitos decorrentes da fusão? }\end{array}$ & \\
\hline 13 & $\begin{array}{l}\text { O que acha que poderia ter sido feito para } \\
\text { a fusão ter sido totalmente bem sucedida? }\end{array}$ & Condicionada às respostas anteriores \\
\hline 14 & E o que poderia ter sido evitado? & Idem \\
\hline 15 & $\begin{array}{l}\text { Qual a importância dos gestores para a } \\
\text { fusão? }\end{array}$ & \\
\hline 16 & $\begin{array}{l}\text { Como os gestores motivaram o grupo à } \\
\text { mudança (fusão)? }\end{array}$ & \\
\hline 17 & $\begin{array}{l}\text { Quais as maiores dificuldades } \\
\text { encontradas pelos gestores? }\end{array}$ & \\
\hline 18 & O que faltou para os gestores? & \\
\hline
\end{tabular}

Pautando-se nos principais pontos de interesse percebidos nas seis entrevistas semiestruturadas, e considerando-se as reflexões construídas com a revisão da literatura, formulou-se um questionário único para ser aplicado a todos os funcionários envolvidos no processo de fusão setorial. Esse questionário teve 6 (seis) "perguntas-chave", apurando características básicas - origem funcional, estágio alcançado pelos setores na fusão, função ocupada pelo servidor durante o processo, nível de escolaridade, faixa etária e tempo de casa -e 25 afirmações a fim de se auferir pela escala de Likert as percepções dos entrevistados sobre o processo de fusão. 
Figura 2: Questionário com as referências teóricas

As 6 (seis) primeiras perguntas, de caráter objetivo, intituladas "perguntas-chave", serviram para definir os traços principais do perfil dos respondentes. As 25 afirmações seguintes foram formuladas pela Escala de Likert a fim de auferir as percepções individuais no tocante a fusão, assim como visões gerais relativas ao processo. Para a apuração dos dados, considerou-se que toda a população, composta por 221 integrantes em exercício, identificados diretamente através das chefias dos setores envolvidos, esteve representada na amostra, composta, ao final, por 171 respondentes.

Gráfico 1: Percentuais de questionários respondidos em relação ao total de formulários distribuídos e em relação ao universo total

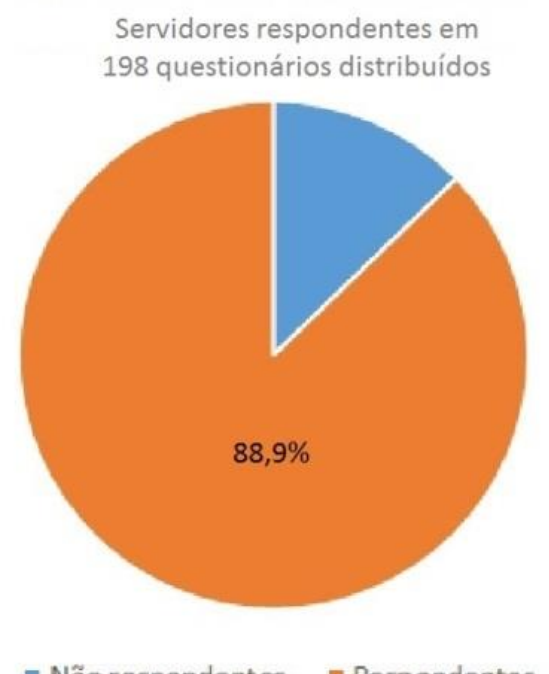

- Não respondentes $\quad$ Respondentes
Servidores respondentes em relação ao universo pesquisado

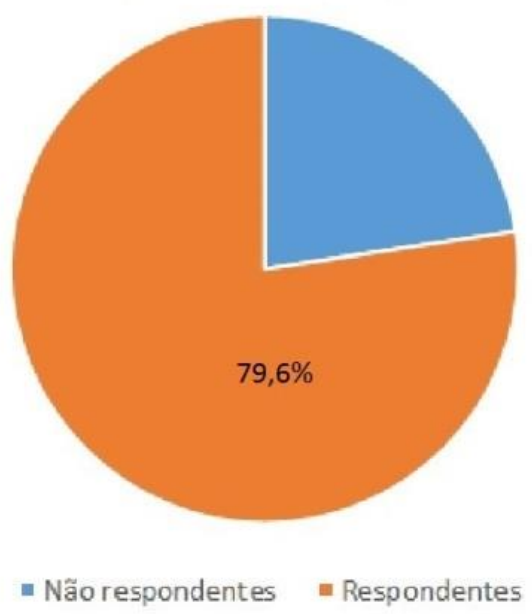

Fonte: o autor, 2016

Cada uma das 25 afirmações apresentadas foi analisada individualmente e entrecruzadas com as 6 (seis) perguntas-chave. 0 entrecruzamento das 6 perguntas-chave com as 25 afirmações produziu um total de 181 gráficos percentuais, entretanto para responder às duas questões de pesquisas aqui propostas foram priorizados os resultados de 94 gráficos do total produzido.

\section{ANÁLISE E DISCUSSÃO DOS RESULTADOS}

Para se proceder a uma análise de resultados sobre atuações de liderança, foi importante saber, antecipadamente nas entrevistas, o que se espera de um líder. Nos depoimentos dos 6 
(seis) entrevistados as expectativas sobre a atuação dos gestores nas fusões setoriais fizeram-se claras. Na fala de um dos depoentes, lembrou-se que um dos desafios das lideranças era "convencer os servidores a irem trabalhar com outros, sem que houvesse uma aproximação prévia, e convencê-los de que aquele procedimento seria benéfico para a instituição e para eles." Foi lembrado ainda que uma de suas funções nas fusões setoriais era minimizar conflitos, que são inevitáveis no processo, e conseguir nivelar conhecimentos e procedimentos entre equipes que sempre operaram de modos distintos. Kavanagh e Ashkanasy (2006), destacam a necessidade de uma gestão voltada para atender aos fatores humanos e culturais nos processos de fusões e de mudanças culturais.

Nos depoimentos colhidos, ao apontarem os desafios enfrentados pelos gestores no processo de fusão, os entrevistados fazem críticas à falta de planejamento, a falta de transparência e a falta de humildade dos responsáveis para reconhecerem erros. Esses relatos, que ilustram parcialmente a 'questão (ii)', remetem ao resultado das investigações de Collins (2011) que revelou que os melhores líderes são pessoas humildes, capazes de se sacrificarem e abrirem mão de seu bem-estar pessoal visando ao bem comum da organização. HASSAN et al. (2013), fala também das relações de troca de alta qualidade possíveis de acontecer quando os líderes são honestos, dignos de confiança, e genuinamente preocupados com o bem-estar de seus seguidores.

Ainda com foco na 'questão (ii)', uma das queixas ao planejamento do processo foi a não previsão de tempo, pelos gestores de topo, para que os servidores pudessem se dedicar ao aprendizado das muitas tarefas novas que surgiram com a fusão. Um depoente ressaltou que o volume de atividades que os servidores executavam já era imenso antes da fusão. Em complemento, ele disse ter tido a sorte de ter uma chefia que detinha conhecimento amplo do funcionamento de tudo e que esta assumiu todos os problemas como se fossem seus. Nesse ponto, faz-se visível que o servidor via seu líder como um "proprietário" e um "campeão", aspectos imprescindíveis para o sucesso das mudanças, segundo Cameron (2008).

Ressaltando deficiências no nível estratégico, o que se junta à 'questão (ii)', um dos depoentes falou na importância em se trabalhar com resultados em um processo de unificação setorial. Ele explicou que "trabalhar com resultados, no início, é sempre difícil por que tem que se fazer uma readequação de toda a estrutura, rever as chefias". Sobre essa revisão dos postos de gestão, Cameron (2008) diz que não somente os líderes atuais da 
organização devem defender as mudanças, mas um grupo de futuros líderes já deve estar sendo preparado para liderar a organização quando as mudanças forem colocadas em prática. Os novos líderes que serão necessários à futura cultura devem ser escolhidos e as diferenças entre os requisitos da liderança atual e os da futura devem ser especificadas. Nesse sentido, as atividades de aprendizagem são determinantes para aprimorar os conhecimentos e competências de liderança.

Em relação aos questionários, apresentamos a análise sobre as opções selecionadas pelos respondentes, em relação às afirmações propostas. Para responder à 'questão (i)', serão aqui consideradas as afirmações 3, 10, 18, 19, 21, 22 e 25 formuladas no questionário aplicado.

Com a afirmação 3, teve-se o intuito de se perceber em que nível de gestão se deu a materialização das fusões propostas. A maioria dos servidores $(32,7 \%+17 \%)$ acreditou ter havido maior peso das estratégias traçadas pelos gerentes de área no processo de fusão do que de um plano estratégico institucional. Voet, Kuipers e Groeneveld (2013) dizem que em um processo planejado "o papel da liderança é geralmente visto como essencial durante a execução da mudança organizacional." E apesar da atenção ficar, em muitos casos, focada na alta administração ou na equipe de coalizão administrativa da mudança, "supervisores diretos desempenham um papel muito importante durante a implementação da mudança".

Gráfico 2: Visão sobre os responsáveis pelas estratégias traçadas

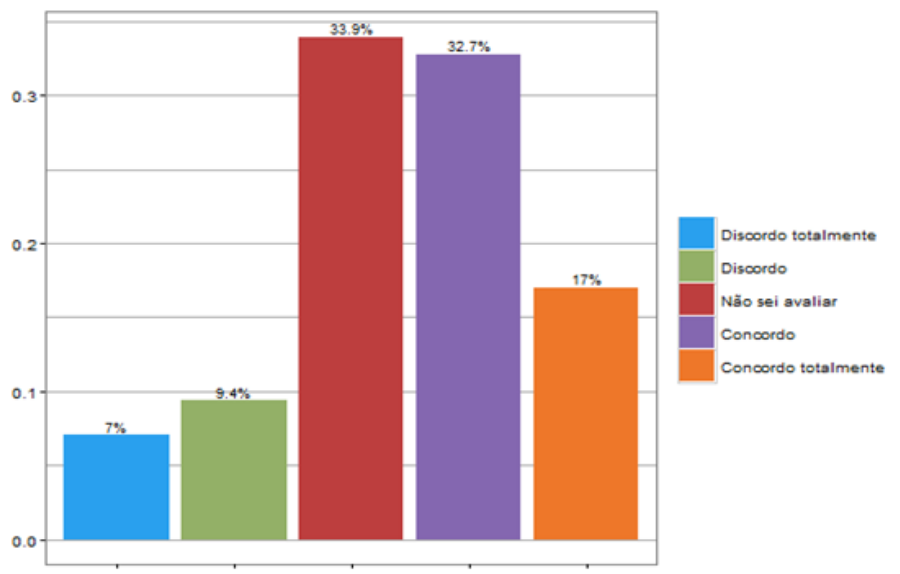

Fonte: o autor, 2016

A afirmação 10 carregou em seu bojo a faculdade de permitir que se procedesse a uma análise do poder de influência dos líderes sobre o grupo. Com apenas $19,9 \%(15,8 \%+4,1 \%)$ de discordâncias, os resultados mostraram que $52,1 \%$ dos respondentes concordaram que a 
conduta dos líderes/gestores foi influenciadora nas reações à mudança, ratificando o observado por Yukl (2009).

Gráfico 3: Influência dos gestores nas reações às mudanças

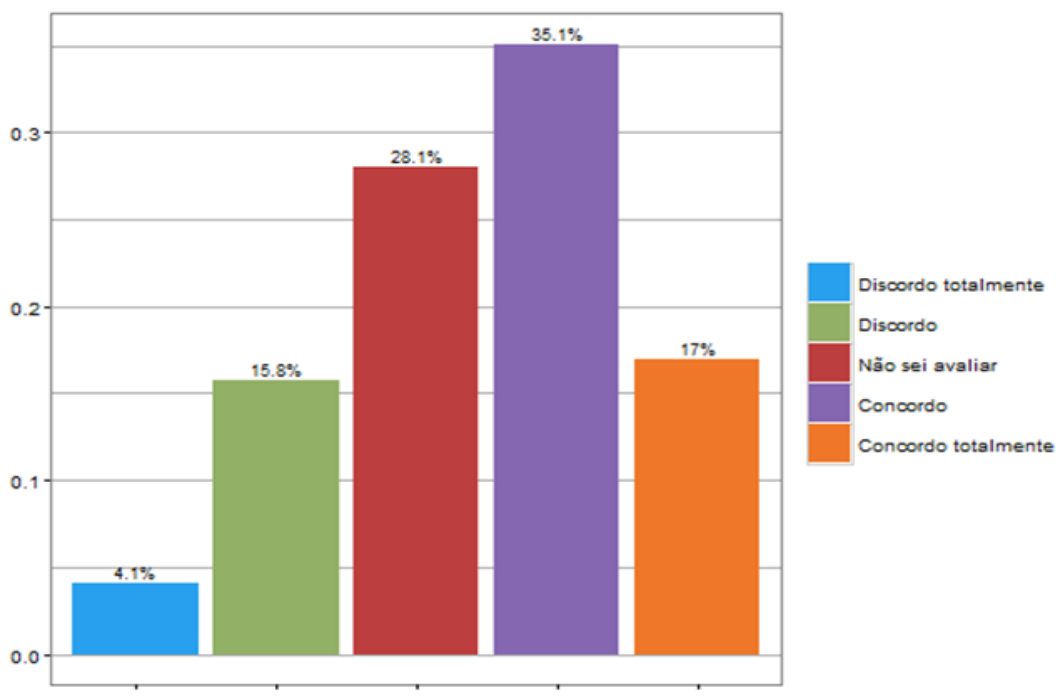

Fonte: o autor, 2016

Na afirmação 18 checou-se a ocorrência de uma estratégia comum no exercício da liderança: a concessão de benefícios para estimular o engajamento dos servidores. Entendendose aqui benefício como qualquer ação que favoreça ou recompense o servidor, $73,7 \%$ (52,6\% + $21,1 \%)$; dos respondentes concordou que tais benefícios se revertem em um maior engajamento de todos os servidores nos processos de trabalho.

Gráfico 4: Resultado de benefícios concedidos pelos líderes

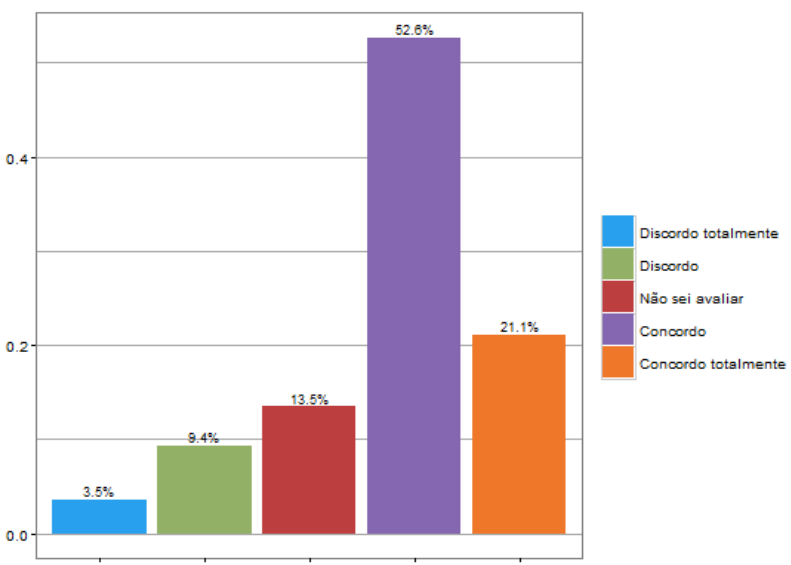

Fonte: o autor, 2016

Essa questão merece observações outras que dizem respeito à conduta geral adotada pela organização que anulou a importância da cessão de benefícios e seguiu por caminho contrário. Desta forma, vale destacar o depoimento do servidor que disse que para o processo 
ter sido bem sucedido "Não [deveria] mexer no bolso das pessoas! Veja, como é que você vai trabalhar mais, muito mais, tendo os seus incentivos pecuniários retirados ou diminuídos?! (...) Mas o que ocorreu mesmo, é que ótimos funcionários perderam suas gratificações com a fusão e aí rolou uma inversão, pois os funcionários foram punidos por trabalharem bem."

Schein (2009) lembra que "a natureza das recompensas e punições conduzem as mensagens. Os líderes podem, rapidamente, conduzir com sucesso suas prioridades, valores e suposições ao vincular conscientemente as recompensas e punições ao comportamento que os afeta." Desta forma, percebe-se que no processo de fusão estudado a decisão de cortes de gratificações, que veio pronta da administração superior, demostrou que a alta administração não se atentou para mecanismos básicos, como os efeitos das punições e recompensas, nas relações de liderança.

$\mathrm{Na}$ afirmação 19, verificou-se a existência de "empoderamentos" no exercício dos gestores. Percebeu-se pelo resultado que uma relativa maioria dos respondentes $(35,7 \%+8,8 \%)$ disse concordar que os gestores souberam delegar autoridade a fim de que os servidores se sentissem mais participativos e responsáveis. Segundo Hassan et al. (2013) "a ética e o empoderamento" de membros da organização são comportamentos suscetíveis de serem associados com a alta qualidade de relacionamentos de troca entre líder e membro.

Gráfico 5: Delegação de autoridade pelos gestores a outrem

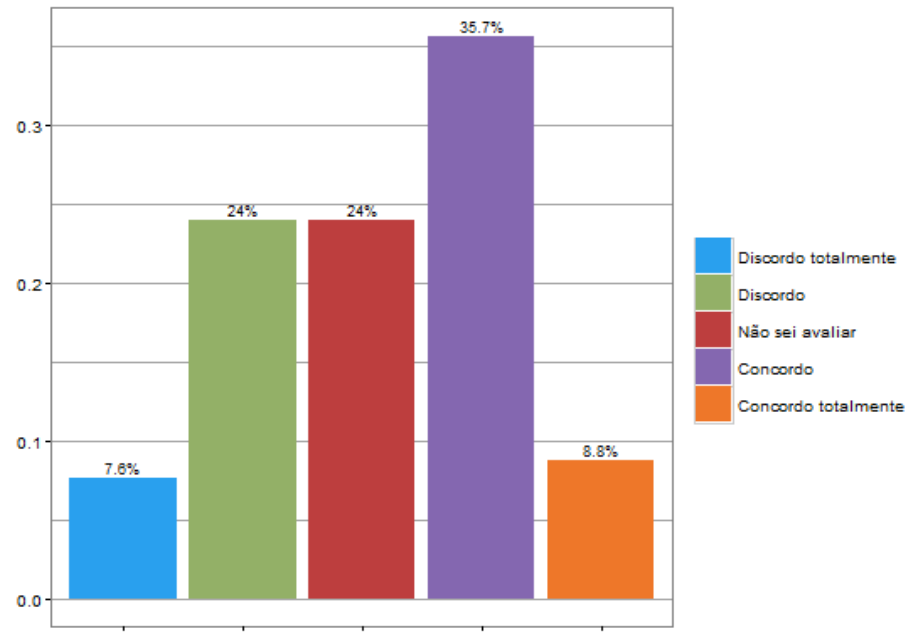

Fonte: o autor, 2016

Na afirmação 21, a lealdade do gestor à organização é o ponto central. Pelos resultados percebe-se que a grande maioria dos respondentes, $73,7 \%(46,8 \%+26,9 \%)$, concorda que essa lealdade do gestor à organização é um fator determinante para o envolvimento das equipes com 
as mudanças. Conforme HASSAN et al. (2013), no cenário atual mundial, marcado por crises morais, as relações de lealdade e compromisso dos membros com as organizações vem sendo cada vez mais valorizadas. Tse, Ashkanasy e Dasborough (2012) colocam como postulado que o relacionamento de alta qualidade demanda lealdade, afeto, contribuição e respeito profissional.

Gráfico 6: Lealdade do gestor à instituição é determinante

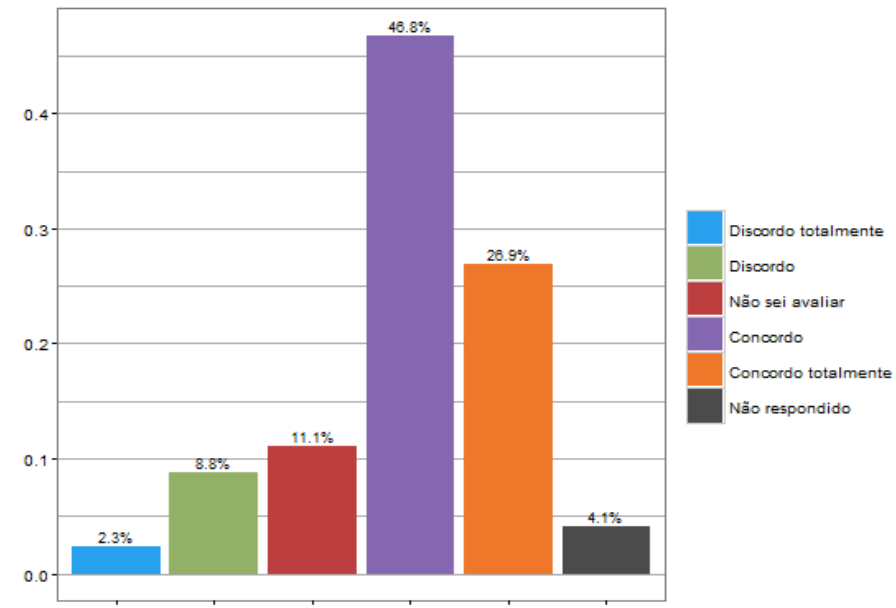

Fonte: o autor, 2016

Ao ser analisada em conjunto com a afirmação 22 , a afirmação 13 , averiguou-se o gestor de órgãos públicos enfrenta pressões de diferentes grupos de interesse, tornando sua atuação vulnerável aos interesses pessoais. $75 \%$ dos respondentes concordou que eles estão suscetíveis a isso, fato que reflete um quadro crítico do funcionalismo público brasileiro marcado pelas práticas das nomeações políticas. O professor Matias-Pereira, expressando-se sobre o sistema estabelecido na Administração Pública, comenta que "quando loteiam cargos no governo, o critério não é de competência nem de postura ética. O critério é político". Esse fato é sem dúvida um empecilho à boa administração e um dos dificultadores nos processos de reestruturações, quando implicam na nomeação de novos gestores.

Na afirmação 22 foi possível ver que a maior parcela dos respondentes, 78,9\% (38\% + 40,9\%), concorda que os cargos em comissão da gestão pública, beneficiando, por vezes, pessoas despreparadas para ocupá-los, é uma realidade e eles podem atrapalhar as mudanças organizacionais. 
Gráfico 7: Despreparo em cargos em comissão podem obstaculizar

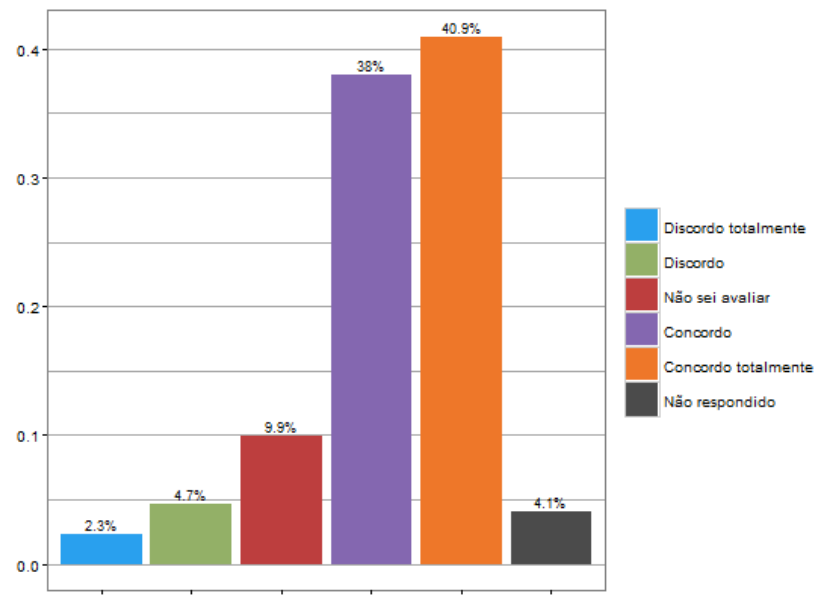

Fonte: o autor, 2016

Moreira (2009) lembra que a livre contratação para cargos em comissão deveria rigorosamente respeitar os princípios constitucionais da legalidade, impessoalidade, moralidade, publicidade e eficiência. Teixeira, Bassotti e Santos (2014) e Coelho e Barros (2021), destacam que na administração pública brasileira, os apadrinhamentos são grandes dificultadores na busca por gestões mais eficazes.

$\mathrm{Na}$ afirmação 25, tentou-se detectar se os gestores haviam desenvolvido boas soluções para minimizar os conflitos interpessoais que surgiram no processo de fusão. A maior parte dos respondeu afirmativamente. Segundo o ponto de vista de Schein (2009), diante das crises o papel das lideranças ganha visibilidade. É quando se pode perceber como líderes lidam com a necessidade de se criar novas regras, valores e procedimentos.

Gráfico 8: Ações para minimizar conflitos

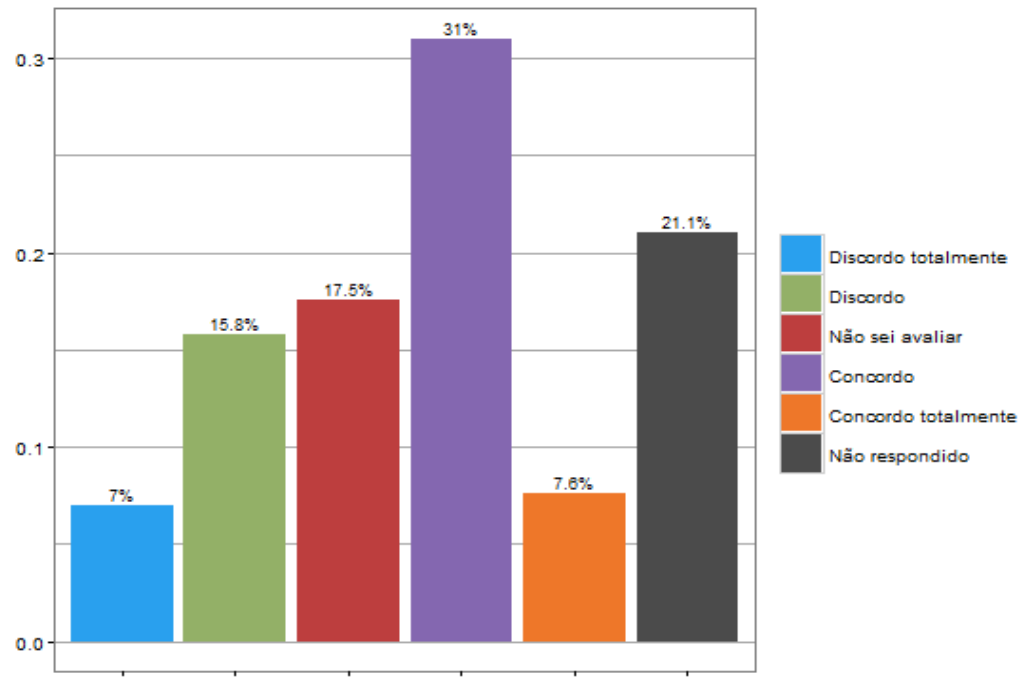


Fonte: o autor, 2016

Em síntese, no tocante à "questão (i)", o que se pode perceber a partir da correlação entre a prática e as concepções teóricas é que apesar da existência de estudos sugerindo formas para se conduzir um processo de fusão, não se pode desconsiderar o que cada caso demanda e o contexto social em que ocorrem, assim como as singularidades de cada grupo (ou organização) envolvido no processo. Desta forma, não se objetivando que se depreenda da literatura um processo padronizador para as práticas das lideranças no processo de gestão de mudanças, percebe-se, a partir dos comparativos ora construídos que existiu satisfatório alinhamento entre as práticas das lideranças identificadas na pesquisa de campo e a literatura científica sobre o tema.

Kuipers (2014), ao mencionar que a resistência à mudança nas fusões, é um tema recorrente nos estudos sobre aquisições de organizações no âmbito da iniciativa privada, lembrou que a literatura vem mostrando ser esse assunto também é uma questão importante no âmbito da gestão pública e que "não parece haver um consenso sobre o que provoca as resistências e como elas podem ser superadas". Destarte, considerando os resultados das afirmações 13 e 22, assim como a revisão da literatura, e desconsiderando as peculiaridades de cada processo de resistência, mesmo que a atuação das lideranças possa em muitos casos minimizá-las, percebe-se, na tentativa de responder à "questão (ii)", que, no referente ao Brasil, as deficiências das lideranças em processos de mudança administrativa no setor público podem se revelar de múltiplas formas. Mas, é consenso que, é na recorrente supremacia dos critérios políticos sobre os critérios técnicos, que resultam na nomeação de gestores mal preparados para ocupar, principalmente, os cargos de alta liderança nas organizações públicas, onde se pode encontrar o fato motivador de muitas das deficiências que se sucedem nos processos de gestão de mudanças na administração pública.

Dentre os resultados obtidos, destacaram-se então que respeitadas as diferenças contextuais de cada caso onde se processa uma gestão de mudança, a literatura científica serve como um bom parâmetro para conduzi-la; que a resistência às mudanças é traço recorrente nos processos de gestão de mudança, seja na esfera da administração pública ou da privada e ainda que a subestimação da gestão de pessoas é uma falha cometida por muitos gestores no universo da administração pública, a qual pode conduzir fusões ou processos similares ao insucesso. 


\section{CONCLUSÕES}

O que se pode perceber a partir da correlação entre a prática e as concepções teóricas, é que apesar de estudos existentes sugerirem formas para se conduzir em um processo de fusão, não se pode desconsiderar as singularidades de cada caso - sejam as especificidades decorrentes do contexto social em que se dão, sejam as particularidades de cada grupo da organização. Há que sempre se considerar esses fatores como componentes dificultadores para a criação de processos padronizadores para fusões setoriais. A título de complementação, vale ainda considerar o mencionado por Kuipers (2014), que diz que apesar das resistências à fusão ser um tema recorrente nos estudos sobre fusões de organizações no âmbito da iniciativa privada, deve-se lembrar que a literatura vem mostrando ser esse um assunto importante no âmbito da gestão pública. Entretanto, "não parece haver um consenso sobre o que provoca as resistências e como elas podem ser superadas". Desta forma, pode-se concluir que encontrar modelos que avaliem inteiramente um processo de integração entre culturas organizacionais distintas ainda se apresenta como um importante desafio para os estudiosos do tema.

Sena Neto (2019) e Agune (2014) destacam que os processos decisórios no mundo corporativo tornaram-se, necessariamente, cada vez mais velozes e as organizações governamentais estão tendo que evoluir sob a pena de se tornarem obsoletas e não conseguirem atender, minimamente, o público em tempos razoáveis e com qualidades aceitáveis. É fato imperativo na modernização da administração pública, que planejamentos estratégicos, reestruturações setoriais e aperfeiçoamentos de processos de trabalho, venham sendo comumente promovidos a fim de se alcançar melhores resultados nos modelos de governança. Apesar das abordagens de Voet, Kuipers e Groeneveld (2013), Kuipers e Groeneveld (2014), Hassan et al. (2013), dentre outras fontes citadas, ressaltarem a importância de as lideranças estarem atentas para o bem estar de seus seguidores e destacarem a importância do engajamento dos colaboradores, ainda se percebe que a subestimação da gestão de pessoas é uma falha cometida por muitos gestores no universo da administração pública e que pode levar fusões e processos similares ao insucesso.

Assim, se a organização não tem, dentre as suas prioridades, o bem-estar dos funcionários e a satisfação profissional, ela tende a experimentar uma alta taxa de 
rotatividade dentre seus colaboradores e, em decorrência, perdas de capital intelectual e mais gastos com novas contratações e treinamentos. Quando se fala em 'rotatividade' de funcionários, raramente se associa diretamente o termo ao universo do serviço público, visto que a estabilidade acaba sendo considerada como um atrativo imperativo para a manutenção dos vínculos empregatícios na administração pública. Isto é fato, mas insatisfações com processos mal geridos podem levá-los comumente a trocarem de setores dentro da organização, a buscarem transferências para outros órgãos ou até mesmo fazerem outros concursos públicos, em busca de carreiras públicas mais satisfatórias.

Esse fato deve ser também complementado sobre a ótica de Bastos e Rowe (2015), que mencionam, que a falta de perspectiva daqueles servidores que não desejam ou não conseguem se lançar em busca de uma carreira nova, principalmente por já se encontrarem no final de uma carreira funcional, gera o discutido entrincheiramento, um comportamento marcado pela acomodação, pois o empregado necessita se manter na organização para garantir os benefícios adquiridos com o decorrer do tempo, assim como a sua própria sobrevivência. Essa acomodação pode ser vista então como o prenúncio de uma resistência às mudanças. Destarte, os servidores entrincheirados podem vir a se tornar o maior desafio para gestores do setor público, pois o que estes esperam de suas equipes de trabalhos é que os indivíduos estejam engajados e demonstrem comprometimento na realização das metas e objetivos da organização, motivações raras quando na condição de entrincheirados. Logo, o entrincheiramento pode, assim, se configurar como um fator representativo em mudanças malfadas contribuindo para as avaliações deficitárias das lideranças abordadas na 'questão (i)'.

Diagnosticadas as deficiências em processos de mudanças administrativas em instituições públicas, tendo como base o alinhamento entre as práticas apuradas no trabalho de campo e as teorias existentes, percebe-se que a pesquisa desenvolvida poderá trazer contribuições futuras na apuração de muitas outras questões correlacionadas aos fluxos relacionais entre lideranças e colaboradores assim como possibilitar o desenvolvimento de investigações visando a produção de estudos preventivos para minimizar impactos e conduzir as fusões a melhores resultados. 


\section{REFERÊNCIAS}

AGUNE, Roberto. Governo no Século XXI. In: Dá pra fazer - Gestão do conhecimento e inovação em governo. (autores Roberto Agune ... [et al.]). São Paulo: Secretaria de Planejamento e Desenvolvimento Regional, p.23-33, 2014.

ARISTOS, D; GEORGIOS, S.; MILTIADIS, C; GRIGORIOS, K. The impact of mergers and acquisitions on corporate culture and employees: the case of aegean \& olympic air, Academy of Strategic Management Journal, v. 17, Issue 1, 2018

ALVES, Paulo Vicente. Gestão Pública Contemporânea. Rio de Janeiro: Editora Alta Books, 2015.

Banks, G. C., Fischer, T., Gooty, J., Stock,G. (2021). Ethical leadership: Mapping the terrain for concept cleanup and a future research agenda, The Leadership Quarterly, 32(2), 1-14

BASTOS, Antonio Virgílio Bittencourt; SOUZA, Janice Janissek de; COSTA, Vânia Medianeira Flores; PEIXOTO, Adriano de Lemos Alves. A Adoção de Novas Práticas de Gestão: explorando o esquema cognitivo dos atores em empresas com diferentes padrões de inovação. Revista de Ciência da Administração, v. 15, n. 31, p. 243-268, set/dez. 2011

BEER, M.; NOHRIA, N. Cracking the code of change. Harvard Business Review, May/June, p. 133-41, 2000.

BURKE, W. W. Organization change: theory and practice. Thousand Oaks: Sage publications, 2010.

BERGUE, Sandro Trescastro. Gestão estratégica de pessoas no Setor Público. 2. ed. Belo Horizonte: Fórum, 2020. p. 15

CAMERON, K. A process for changing organizational culture. In: CUMMIINGS, T. G. (Org.), Handbook of Organizational Development. California: Sage Publications, 2008.

Carson, K. D.; Bedeian, A. G. Career commitment: construction of a measure and examination of its psychometric properties. Journal of Vocational Behavior, v. 44(3), p. 237-262, 1994 Coelho, C.C.; Barros, A. Padrinhos e caciques: o lado sombrio da atividade corporativa na captura do Estado. Curitiba: Revista Eletrônica de Ciência Administrativa, v.20, n.1, p. 14-42, Jan-Abr, 2021

COLLINS, J. Level 5 Leadership: The triumph of Humility and Fierce Resolve. In: On leadership. Boston: Harvard Business Review Press. P.115 - 136, 2011.

CONGER, J. A.; KANUNGO, R. N. The empowerment process: Integrating theory and practice, Academy of Management Review, v.13, pp. 471-182, 1988. 
DAM, van K. OREG, S.; SCHYNS, B. Daily work contexts and resistance to organizational change: The role of leaders-member exchange, development climate, and change process characteristics. Applied Psychology, v. 57(2), p. 313-334, 2007.

DEDA, R. Elevado número de cargos em comissão facilita o nepotismo. A Gazeta do Povo, Curitiba, 14. set. 2008. Disponível em: <http://www.gazetadopovo.com.br/vidapublica/elevado-numero-de-cargos-em-comissao-facilita-o-nepotismob6e2yaib0y6ggk5lykri4cy1a> Acesso em 29. out. 2015.

Dîrvă, C., Rădulescu, A. S. (2018). Managing resilience to change in merger and acquisitions. Romanian Economic Journal, 21(68), 145-160.

Dom F. R., Ahmad A. (2019). An impact of cultural change on employees engagement and organization performance: a literature review, ICBEISS 2019: International Conference on Business, Education, Innovation \& Social Sciences, Kuala Lumpur, Malaysia, 29 June

DRUCKER, P. F. Fator humano e desempenho. 1. ed., São Paulo: Cengage Learning, 1981.

FAGANELLO, Cláudia Piccoli. Balanço do Gerencialismo: análise da influência do modelo de administração pública gerencial no período de 1995 a 2017. Dissertação (Mestrado) - Instituto de Filosofia e Ciências Humanas, Universidade Federal do Rio Grande do Sul, Porto Alegre, 2017

HAMEED, I KHAN, A. K.; SABHARWAL, M.; ARAIN, G. A,; Irfan HAMEED, I. Managing Successful Change Efforts in the Public Sector: An Employee's Readiness for Change Perspective. Review of Public Personnel Administration, USA, v. 39, Issue 3, 1-24, 2019

HASSAN, S.; MAHSUD, R.; YUKL, G.; PRUSSIA, G. E. Ethical and empowering leadership and leader effectiveness, Journal of Managerial Psychology, v. 28, p.133-146, 2013.

HOFSTEDE, G. Cultures and Organizations: Software of the Mind. 1. ed., USA: McGrawHill, 1991.

HOLT, D. T.; ARMENAKIS, A. A.; FEILD, H. S.; HARRIS, S. G. Readiness for organizational change: The systemic development of a scale. The Journal of Applied Behavioral Science, v. 43(2), p. 232-241, 2007.

HOGG, M; VAN KNIPPENBERG, D.; RAST, D. Intergroup leadership in organizations: Leading across group and organizational boundaries. Academy of Management Review v. 37(2), p. 232-255, 2012.

KAVANAGH M. H.; ASHKANASY N. M. The Impact of Leadership and Change Management Strategy on Organizational Culture and Individual Acceptance of Change during a Merger. British Journal of Management, v. 17, p. 81-103, mar. 2006.

KOTTER, J. P. Leading change. Boston: Harvard Business Review Press, 1996. 
KUIPERS, Ben; GROENEVELD, Sandra. De kracht van High Performance Teams - Zes ingrediënten voor excellent presteren in de publieke sector. Amsterdam: Mediawerf Uitgevers, 2014

KUIPERS, B. S.; HIGGS, M. J.; KICKERT, W. J. M.; TUMMERS, L. G.; GRANDIA, J.; VAN DER VOET, J. The management of change in public organisations: A literature review. Public Administration, v. 92, n. 1. P. 1 - 20, Newcastle, 2014.

LUBIS, Fitri \& HANUM, Farida. (2020). Organizational Culture. YICEMAP 2019: International Conference on Educational Management/Administration and Pedagogy, Yogyakarta, Indonesia.

MATIAS-PEREIRA, José. Curso de Administração Pública: foco nas instituições e ações governamentais. 4. ed. São Paulo: Atlas, 2014. p. 123-135

MEIRELLES, Hely Lopes. Direito administrativo brasileiro. 42. ed. São Paulo: Malheiros, 2016.

MOREIRA, A. M. F. A arte de prevaricar na designação de ocupantes de cargos em comissão. jul. 2009. Disponível em:<http://jus.com.br/artigos/13179/a-arte-de-prevaricar-na-designacao-deocupantes-de-cargos-em-comissao> Acesso em 29. out. 2015.

NADLER, D. A.; THIES, P. K.; NADLER, M. B. Culture Change in the Strategic enterprise: Lessons from the Field. In: COOPER, C. L.; Carwright, S.; EARLY, P. C. The International Handbook of Organizational Culture and Climate. Chichester: John Wiley\& Sons Ltda, 2001.

NOGUEIRA, José Marcelo Maia; OLIVEIRA, Kátia Michelle Matos de; VASCONCELOS; Alan Pereira de; OLIVEIRA, Leonel Gois Lima. Estudo exploratório da eficiência dos Tribunais de Justiça estaduais brasileiros usando a Análise Envoltória de Dados (DEA). Rio de Janeiro: Revista de Administração. Pública, v.46(5), p.1317 - 1340, set. - out. 2012.

OLIVEIRA, A. F. Identificação organizacional. In: Siqueira, Mirlene Maria Matias (org.). Medidas do comportamento organizacional: Ferramentas de diagnóstico e de gestão. Porto Alegre: Artmed, p.181 - 190, 2008.

OREG, S. Personality, context, and resistance to organizational change. European Journal of Work \& Organizational Psychology, (2006).

Perides, M. P. N., Vasconcellos, E. P. G., Vasconcellos, L. (2020). A gestão de mudanças em projetos de transformação digital: estudo de caso em uma organização financeira. Revista de Gestão e Projetos, 11(1), 54-73. doi:http://dx.doi.org/10.5585/gep.v11i1.16087

PIDERIT, S.K. Rethinking resistance and recognizing ambivalence. Academy of Management Review, v. 25, n. 4, p. 783-94, 2000.

PIETERSE, Jos H.; CANIELS, Marjolein C. J. HOMAN, Thijs. Professional discourses and resistance to change. Journal of Organizational Change Management, v. 25, n. 6, p. 798-818, 2012. 
PINHO, Ana Paula Moreno; BASTOS, Antônio Virgilio Bittencourt; ROWE, Diva Ester Okazak. Diferentes Vínculos Indivíduo-Organização: Explorando Seus Significados entre Gestores, 3. ed. especial, Rio de Janeiro: RAC, v. 19, art. 3, pp. 288-304, Out. 2015.

PUHL, C.; PROCÓPIO M. L. Burocracia ou gerencialismo: um estudo de caso sobre a administração do Poder Judiciário Federal. XXXVIII Encontro da AMPAD: Rio de Janeiro, set. 2014.

RODRIGUES, Ana Paula Grillo; BASTOS, Antônio Virgílio Bittencourt. Os vínculos de comprometimento e entrincheiramento presentes nas organizações públicas. Revista de Ciência da Administração, v. 15, n. 36, p.143-158, ago. 2013.

ROUSE, T.; HARDING, D. Due diligence humana. Harvard Business Review - Brasil, jan.2012. Disponível em http://hbrbr.com.br/due-diligence-humana/. Acesso em: 02. fev. 2021.

Salem, M., Van Quaquebeke, N., Besiou, M., Meyer, L. (2019). Intergroup Leadership: How leaders can enhance performance of humanitarian operations. Production and Operatons Management, 28(11), 2877-2897.

SAMPAIO, J. Suspensão ameaça serviço público. Diário do Nordeste, Fortaleza, 20.set.2015. Disponível em:

<http://diariodonordeste.verdesmares.com.br/cadernos/nacional/suspensao-ameacaservico-publico-1.1390994>. Acesso em: 30. set. 2015.

SCHEIN, E. H. Cultura Organizacional e Liderança. São Paulo: Atlas, 2009.

SENA NETO, B. G. Governo eletrônico e-Gov. Natal: IFRN, 2019.

SILVA JUNIOR, Domingos da; COSTA, Francisco José. Mensuração e Escalas de Verificação: uma Análise Comparativa das Escalas de Likert e Phrase Completion. São Paulo: Revista Brasileira de Pesquisas de Marketing, Opinião e Mídia, v. 15, p. 1-16, out. 2014.

SCHOONENBOOM, Judith; Designing Mixed Methods Research by Mixing and Merging Methodologies: A 13-Step Model. American Behavioral Scientist, v. 62(7), p. 998-1015, 2018

TEE, E.; ASHKANASY, N. M.; PAULSEN, N. The influence of follower mood on leader mood and task performance: An affective, follower-centric perspective of leadership. The Leadership Quarterly, v.24, p. 496-515, ago. 2013.

TEIXEIRA, H. J.; BASSOTTI, I. M.; SANTOS T. S. (org.). Mérito, desempenho e resultados: ensaios sobre gestão de pessoas para o setor público. São Paulo: FIA/USP, p. 16, 2014.

TROMPENAARS, F.; HAMPDENTURNER, C. Riding the Waves of Culture: Understanding Cultural Diversity in Business. London: Nicholas Brealey Publishing, 2000.

TSE, H. H. M.; ASHKANASY, N. M.; DASBOROUGH, M T, Relative leader-member exchange, negative affectivity and social identification: $A$ moderated-mediation examination, The Leadership Quarterly, v.23, p. 354-366, jun. 2012. 
VAGARINHO, J. P. Como identificar a originalidade num artigo científico ou numa tese de doutoramento? (How to identify originality in a scientifi c manuscript or in a doctoral thesis?) Educar em Revista, Curitiba, Brasil, v. 35, n. 73, p. 181-207, jan./fev. 2019

VAN KNIPPENBERG, D. and HOGG, M. A. A social identity model of leadership effectiveness in organizations. In: STAW, B.; KRAMER, R. M. (eds.), Research in Organizational Behavior, Greenwich: JAI Press, v. 25, p. 245-297, 2003.

VOET, Joris van der; KUIPERS, Ben; GROENEVELD, Sandra. Implementing change in public organizations: The relationship between leadership and affective commitment to change in a public sector context. Paper presented at the 11th Public Management Research Conference, Madison, Wisconsin, June 20-22 2013.

WEBER, Y. The effects of top management culture clash on the implementation of mergers and acquisitions. Tese de doutorado. University of South Carolina, 1989.

WEBER, Y.; SCHWEIGER, D. M.; LUBATKIN, M. H. Cultural clash in mergers and acquisitions: a longitudinal study on the acquired top management turnover. Trabalho não publicado apresentado na Reunião Anual da Academy of Management, Las Vegas, Nevada. 1992.

WEBER, Y. Corporate Culture Fit and Performance in Mergers and Acquisitions, Human Relations, v. 49(9), p. 1181-1202, 1996.

WEBER, Y. Development and Training at Mergers and Acquisitions. Procedia - Social and Behavioral Sciences, v. 209, p. 254 - 260, dez. 2015.

YUKL, Gary. Leadership in organizations. Global Edition, Harlow:Pearson Education Limited, 2013. 